\title{
A new technique for the assessment of pulmonary regurgitation and its application to the assessment of right ventricular function before and after repair of tetralogy of Fallot
}

\author{
ANDREW N REDINGTON, PAUL J OLDERSHAW, ELLIOT A SHINEBOURNE, \\ MICHAEL L RIGBY
}

From the Cardiac Department, Brompton Hospital, London

SUMMARY Biplane right ventriculograms with simultaneous high fidelity pressure recordings were obtained in 24 patients with tetralogy of Fallot. Twelve patients were studied before repair and 12 were studied 67 (42) months after radical surgical repair without the use of a transannular patch. In the patients who had repair right ventricular end diastolic and end systolic volume indices were higher, and the ejection fraction was lower. Time to peak ventricular filling and the peak rate of ventricular filling were also lower in this group and there was a significant relation between peak filling rate and ejection fraction. Postoperative pressure-volume loops from nine patients showed an increase in cavity volume during the decline in right ventricular pressure, which indicated pulmonary regurgitation. The mean regurgitant volume for the group correlated with end diastolic volume index, stroke volume index, and peak filling rate, but not with ejection fraction.

These data show that both systolic and diastolic abnormalities of right ventricular function are detected in most patients after radical repair of tetralogy of Fallot. The reduction of ejection fraction previously reported in these patients is unrelated to the degree of pulmonary regurgitation and primarily reflects an impairment of contractile function that presumably is related to intraoperative events.

Tetralogy of Fallot accounts for approximately $10 \%$ of all cases of congenital heart disease. The introduction of systemic to pulmonary shunt procedures in the late 1940 s revolutionised the treatment of these patients. Nowadays most patients have surgical correction, often without prior systemic to pulmonary shunting. ${ }^{1}$ Surgical mortality is low and short term relief of symptoms excellent. ${ }^{2}$ The operation is performed under cardiopulmonary bypass, usually via a right ventriculotomy, and in recent years interest has centred around the effects of operation on ventricular function. Before repair left ventricular function was abnormal in many patients, ${ }^{34}$ but it did not deteriorate after operation. ${ }^{3}$ The reverse seems to be true for right ventricular function. Right ven-

Requests for reprints to Dr Andrew N Redington, Cardiac Department, Brompton Hospital, Fulham Road, London SW3 6HP.

Accepted for publication 12 January 1988 tricular volumes and ejection fractions were normal before operation, ${ }^{35}$ but deteriorated after repair. ${ }^{36-9}$ To date the cause of this deterioration in right ventricular function after corrective operation has not been adequately explained. Residual right ventricular volume load (pulmonary regurgitation or residual ventricular septal defect), chronic hypoxia before operation, and the direct effects of right ventriculotomy have all been implicated..$^{3-9}$ Previous studies were restricted to measurements of ejection fraction with or without measurements of end diastolic and end systolic volumes, and patient subgroups were often poorly defined, making interpretation of their results difficult. Furthermore, there are no data on other indices of right ventricular function such as ventricular filling and emptying rates and pressure-volume relations, which may provide additional information on the pathogenesis of any abnormalities of function.

We studied right ventricular function in two discrete groups of patients. Twelve were studied 
before repair and 12 symptom free patients, in whom there was no evidence of residual ventricular septal defect or significant right ventricular outflow tract obstruction, were studied after repair. Because we obtained simultaneous pressure and volume data we were able to compare indices of systolic and diastolic function other than ejection fraction and simple ventricular volumes. We were also able to assess the volume of pulmonary regurgitation and its effects.

\section{Patients and methods}

\section{GROUP I}

We studied 12 patients aged from eight months to seven years (mean (SD) $42 \cdot 2$ (28) months) before definitive repair. In six patients a modified Blalock shunt had been performed 14 (11) months before because of severe hypercyanotic attacks in infancy. The remainder were studied before any operation. No patient was taking cardioactive medication. Arterial oxygen saturation at the time of cardiac catheterisation ranged from $69 \%$ to $95 \%$ and the haemoglobin concentration was 158 (20) g/l. Right ventricular peak systolic pressure was $68(7) \mathrm{mm} \mathrm{Hg}$ and right ventricular end diastolic pressure was 5 (3) $\mathrm{mm} \mathrm{Hg}$. All patients were undergoing cardiac catheterisation under general anaesthesia as a routine part of their assessment before radical surgical repair.

\section{GROUP 2}

We studied the 12 patients in this group (age 89 (54) months) 67 (42) months after definitive repair. They were all symptom free, leading unrestricted lives, and taking no medication. They were selected on an informal basis when they presented for routine out patient follow up; parents gave their informed consent for follow up cardiac catheterisation in each child. All operations were performed with surface cooling and during cardiopulmonary bypass. We repaired the ventricular septal defect and enlarged the right ventricular outflow tract via a right ventriculotomy. In one patient relief of outflow tract obstruction was satisfactory without an outflow tract patch, but in the remainder the outflow tract was widened with a synthetic graft (woven Dacron). None of the patients had transannular repair (extending the patch across the pulmonary valve annulus). Six patients already had systemic-to-pulmonary shunts because of severe hypercyanotic attacks in infancy. These were taken down at the time of repair.

On clinical examination early diastolic murmurs were audible in four of the patients and short systolic murmurs were present over the pulmonary area in six. The postoperative electrocardiogram showed complete right bundle branch block in all patients.
No patient had electrocardiographic or clinical $\underset{\mathbb{T}}{\stackrel{T}{\Phi}}$ evidence of arrhythmia. The haemoglobin concen- $\frac{\varrho}{7}$ tration was lower than in group 1 (124 (9) g/l, p $<.$. $0.001)$. Cardiac catheterisation was performed $\vec{F}$ during general anaesthesia with alphaxalone- $\stackrel{\rho}{\rightarrow}$ alphadolone acetate (Althesin) after premedication with trimeprazine. Mean (SD) aortic oxygen satura- $\frac{\bar{\sigma}}{\bar{N}}$ tion was $97(1) \%$ and there was no evidence of $\frac{\sigma}{\sigma}$ intracardiac shunting in any patient. The right $\propto$ ventricular systolic pressure in this group was 32 (7) $\mathrm{mm} \mathrm{Hg}$, and only two patients had peak systolic $\vec{\circ}$ pressures of $>40 \mathrm{~mm} \mathrm{Hg}$ ( 44 and $48 \mathrm{~mm} \mathrm{Hg}$ respectively). Right ventricular end diastolic pres- $\vec{\omega}$ sure was not significantly different from that in group $\frac{\rho}{2}$ 1 (6 (3) $\mathrm{mm} \mathrm{Hg})$. The peak to peak right ventricle to pulmonary artery pressure drop was $<20 \mathrm{~mm} \mathrm{Hg}$ in all patients (mean $7 \mathrm{~mm} \mathrm{Hg}$, range 0-19).

\section{METHODS}

Angiography

Biplane right ventriculograms were obtained in the $\subseteq$ $30^{\circ}$ right anterior oblique and $60^{\circ}$ left anterior $₹$ oblique projections after the injection of $1.0-1.5 \mathrm{ml} / \overrightarrow{0}$ $\mathrm{kg}$ of radiographic contrast medium. The cinean- $\infty$ giograms were recorded at a frame rate of 50 frames per second when the heart rate was less than 100 beats per minute, and 75 frames per second when the heart rates exceeded 100 beats per minute. A mark, coinciding with the $R$ wave of the patient's electrocardiogram was recorded on the film. At the end of the study we performed a calibration sequence. This consisted of recording the effect of a $10 \mathrm{~cm}$ shift of the patient perpendicular to the two image intensifiers. This was done immediately after angiography, while the catheter remained in the right ventricle. Thus the magnification factor for each view could be calculated from the shift of the catheter tip according to the formula:

$$
\text { Magnification factor }=\frac{\text { observed shift }(\mathrm{cm})}{10 \mathrm{~cm}}
$$

This method has advantages over those that use grids or calibration objects because no assumptions need to be made about the position of the ventricle.

\section{Pressure measurements}

Pressure was measured simultaneously with the biplane ventriculograms by use of $5 \mathrm{~F}$ or $7 \mathrm{~F}$ micromanometer tipped catheters (Millar Instru- 0 ments Inc). The $7 F$ catheter incorporated a fluid $\stackrel{\square}{\overparen{D}}$ filled lumen. The $5 \mathrm{~F}$ catheters did not have a fluid $\stackrel{\circ}{?}$ filled lumen and when these catheters were used 0 ventriculography was performed with a fluid filled $\vec{O}$ catheter, usually introduced into the right ventricle $\stackrel{\mathbb{D}}{\circ}$ retrogradely from the femoral artery, or $\mathbb{\otimes}$ anterogradely via the ipsilateral femoral vein. The $\frac{\circ}{2}$ 
micromanometers were calibrated against an electrical reference before insertion and checked against the pressure recorded via the fluid filled catheter after insertion. Recordings were made on paper at 100 or $200 \mathrm{~mm} / \mathrm{s}$ along with the patient's electrocardiogram and a mark coinciding with the appearance of contrast medium in the ventricle. Recordings were available from all patients in group 1 and in 11 of the 12 patients studied in group 2.

\section{Analysis}

We excluded all extrasystoles, all complexes that immediately followed extrasystoles, and all complexes recorded during injection of contrast. Angiograms were manually digitised frame by frame throughout the selected cycle in both angiographic views by a Summagraphics digitising plate interfaced with a Prime 750 computer. Right ventricular volumes were calculated from the biplane ventriculograms and corrected by regression equations obtained from a cast study previously described in detail. ${ }^{10}$ Briefly, our method for measuring right ventricular volume divides the ventricle into 40 equal slices along its long axis. Each slice is assumed to be an ellipsis (with the major and minor dimensions derived from the two angiographic projections). Figures 1 and 2 show examples of computer derived three dimensional constructions obtained by this method. The consistent overestimation of actual volume can be corrected by applying the appropriate regression equation (for $30^{\circ}$ right anterior oblique and $60^{\circ}$ left anterior oblique projections; actual volume $=0.82$ (calculated volume) $+0.68 \mathrm{ml}, \mathrm{r}=$ $0.99, \mathrm{p}<0.001$, SEE (4) $\mathrm{ml}){ }^{10}$ The corresponding pressure trace was digitised by the same equipment and stored on magnetic tape, along with the volume data, for later analysis.

We derived the following variables from these stored data:

(a) Right ventricular end diastolic volume indexThis was taken as the maximum value on the volumetime curve (see fig 3) and corrected for body surface area (expressed in $\mathrm{ml} / \mathrm{m}^{2}$ ). End systolic volume was taken as the minimum cavity volume and was similarly standardised for body surface area. Stroke volume index (SVI) was calculated as: SVI = end diastolic volume index minus end diastolic volume index $\left(\mathrm{ml} / \mathrm{m}^{2}\right)$.

(b) Right ventricular ejection fraction-This was calculated in the usual way: ejection fraction = stroke volume $\div$ end diastolic volume $\times 100(\%)$.

(c) Right ventricular filling and emptying ratesThese values were obtained from the first derivative of the volume-time curve. The raw volume data were first smoothed by a three point moving-average filter and then differentiated with respect to time (fig 4).

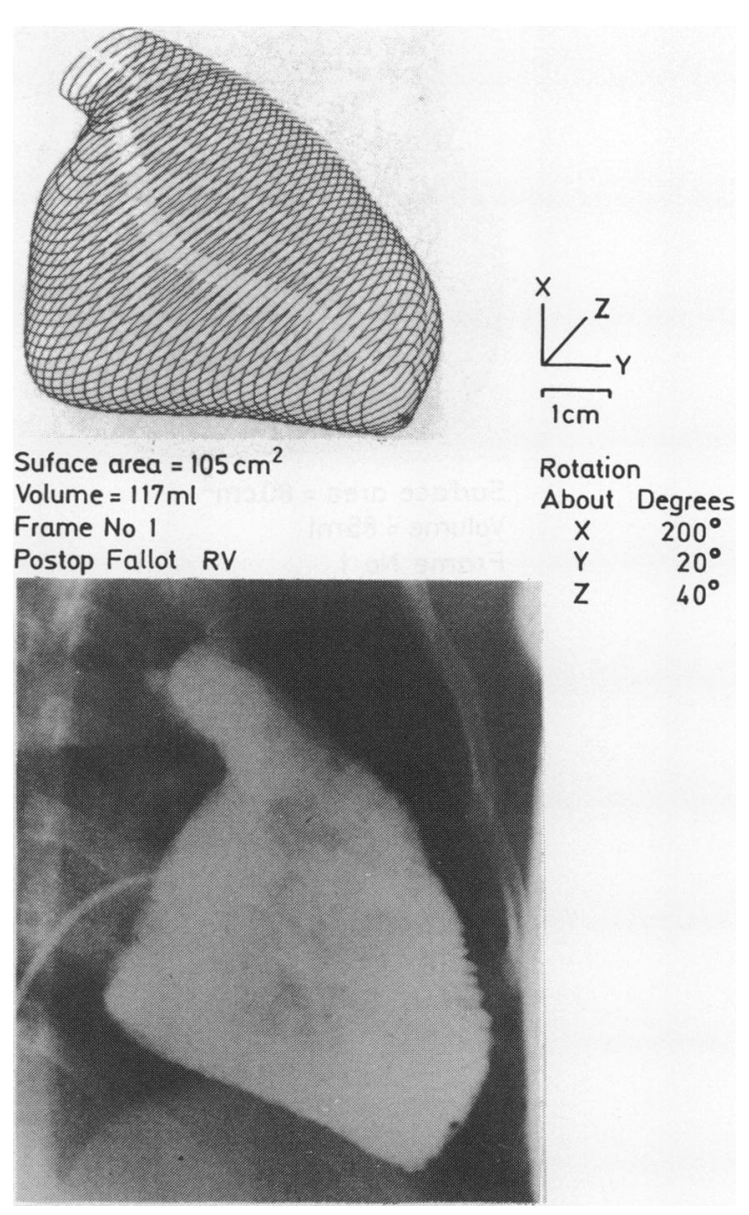

Fig 1 Computer derived three dimensional reconstruction of the right ventricle obtained from a patient after repair. The right oblique view of the biplane angiogram is shown for comparison.

The curve generated has a negative component corresponding to ventricular emptying, a biphasic positive deflection corresponding to an early passive phase of ventricular filling, and a later deflection corresponding to filling resulting from atrial contraction. The peak ventricular filling rate during passive filling was taken as the peak positive deflection during the initial early filling phase. Occasionally only one peak was seen, especially at higher heart rates, and under these circumstances the maximum value of the single peak was used. Peak rates of filling and ejection were standardised by dividing by end diastolic and stroke volumes (units $\mathrm{s}^{-1}$ ).

(d) The time taken to reach peak ejection and peak filling rates was also recorded. Time to peak ejection was measured as the time from the $Q$ wave of the 


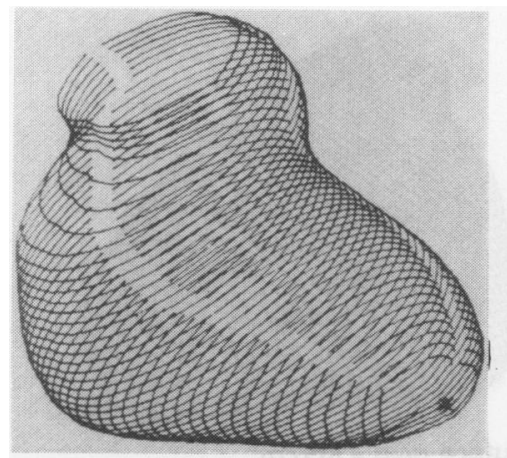

Surface area $=80 \mathrm{~cm}^{2}$

Volume $=85 \mathrm{ml}$

Frame No 1

Postop Fallot

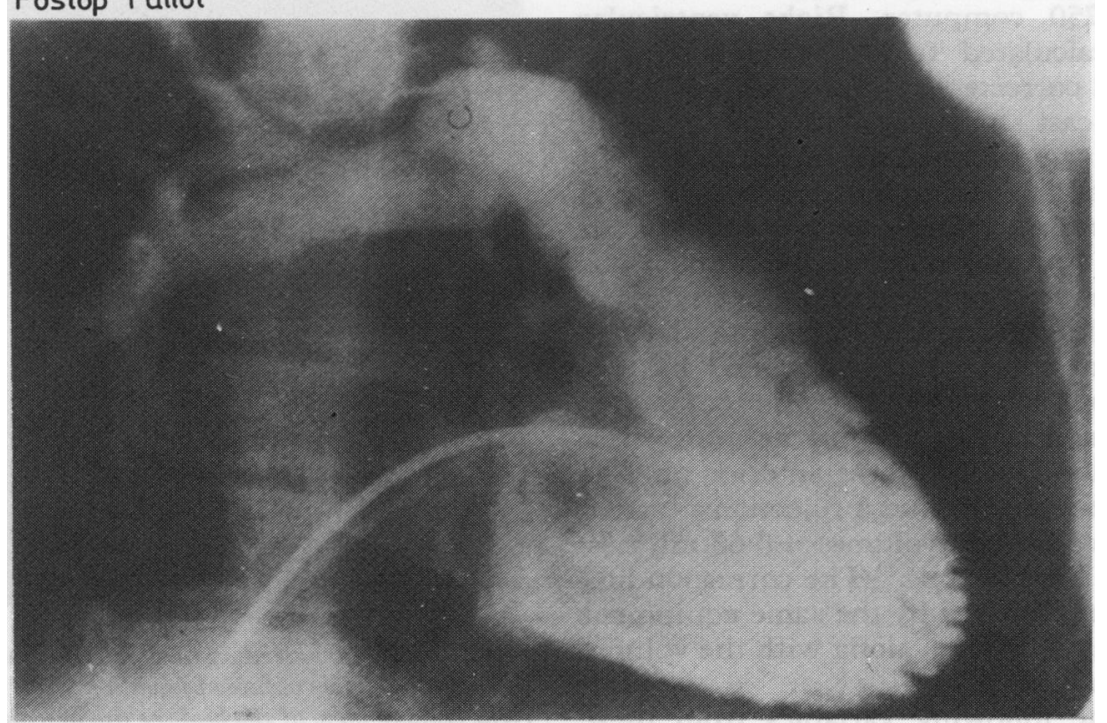

Fig 2 Three dimensional reconstruction from a patient with a discrete aneurysm of the right ventricular outflow tract.

electrocardiogram to the time of peak ejection. Time to peak filling was measured as the time from the point where the DVol/Dt curve crossed the zero line to the time of peak filling rate.

(e) Pressure volume loops-These were constructed by combining the simultaneous pressure and volume curves. The construction and interpretation of these loops is described in detail in a previous publication. $^{10}$

Systolic stroke work was measured from the loops by automatic planimetry of the area enclosed by the loop and subsequently corrected for body surface area $\left(\mathrm{J} /\right.$ beat $\left./ \mathrm{m}^{2}\right)$. The cycle efficiency is the ratio of the area of the loop to that of a square or rectangle that would just enclose it $^{11}$ - that is, the ratio of actual stroke work to the maximum work possible for ventricle with the same pressure characteristics an stroke volume.

\section{Assessment of pulmonary regurgitation}

Measurement of pulmonary regurgitation from pre\% sure-volume loops has not been described before. [T nine of the 11 loops obtained from patients studied after definitive repair we saw an increase in riglä ventricular volume during a fall in pressure (fig 5. . Ventricular filling began when right ventriculap pressure was well above that of peak right atri丝 pressure. In the absence of filling through the tricupid valve, through a ventricular septal defect (excluded by oximetry and angiography), or 

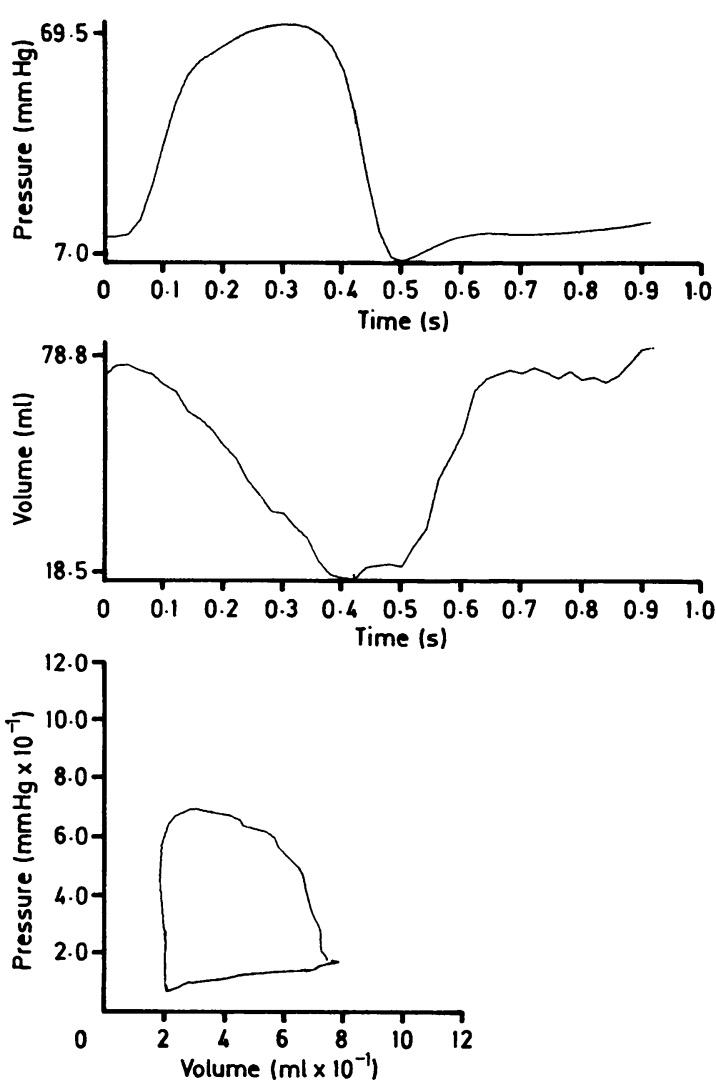

Fig 3 Plots showing simultaneous pressure and volume curves throughout the cardiac cycle. The resultant pressurevolume loop, taken from a preoperative patient, shows a well defined period of isovolumic relaxation with no evidence of volume increase during pressure decline (fig 5).

continued injection of radiographic contrast (we analysed only beats occurring after the end of injection), this increase in ventricular volume must be secondary to pulmonary regurgitation. The pulmonary regurgitant volume during the pressure fall was measured as the change in volume that occurred between the point of minimum cavity dimension to the point where right ventricular pressure had fallen to a level equivalent to that of peak right atrial pressure (recorded before angiography). This volume was expressed in absolute terms $\left(\mathrm{ml} /\right.$ beat $/ \mathrm{m}^{2}$ body surface area) or as a percentage of the total stroke volume. A pulmonary regurgitant volume of $>5 \mathrm{ml} /$ beat $/ \mathrm{m}^{2}$ body surface area was considered to be significant

STATISTICAL ANALYSIS

Variables were expressed as the mean (1 SD). We used standard $t$ tests to compare normally distributed group data, and the Mann-Whitney $U$ test when normal distribution of the data could not be demonstrated. The null hypothesis was rejected when $p<$ $0 \cdot 05$. We tested for correlation between variables by linear regression analysis by the method of least squares.

\section{Results}

Tables 1 and 2 show the raw data for each patient. Right ventricular end diastolic volume index was significantly higher in group 2 than in group $1(63.3$ $(17 \cdot 7)$ v 88.1 (33) $\left.\mathrm{ml} / \mathrm{m}^{2}, \mathrm{p}<0.05\right)$. End systolic volume index was also higher after definitive repair (23.7 (11.1) v $\left.41.3(18.6) \mathrm{ml} / \mathrm{m}^{2}, \mathrm{p}=0.012\right)$; and although there was a tendency towards a high stroke volume in group 2 this difference was not statistically significant $\left(39 \cdot 6(13 \cdot 1) v 46 \cdot 7(16 \cdot 3) \mathrm{ml} / \mathrm{m}^{2}, \mathrm{p}=\mathrm{NS}\right)$.

When the subgroup of unoperated patients in group 1 was compared with those with shunts there was a tendency for end diastolic volume index to be increased in the group with shunts $(60(21) v 66$ (14) $\mathrm{ml} / \mathrm{m}^{2}$ ) and for ejection fraction to be lower $(65(8) v$ 59.5 (13)) but neither of the differences was statistically significant. Right ventricular ejection fraction was lower after repair $(62.4(11.1) v 53.8(6.5), \mathrm{p}<$ $0.05)$ and correlated significantly with end systolic volume $(r=-0.72, p<0.01)$ and peak filling rate $(r=0.56, p<0.05)$ in this group.

Peak rate of ejection corrected for end diastolic volume was significantly lower in patients studied after repair $\left(4.2(1.4) v 2.6(0.5) \mathrm{s}^{-1}, \mathrm{p}<0.005\right)$. Peak rate of ventricular filling corrected for end diastolic volume or stroke volume was also reduced after repair $(6.4(2.6) v 3.6(1.4), \mathrm{p}<0.01$ and $10.3(3.9) v$ $6.66(2.0), \mathrm{p}<0.001$, respectively). Time to peak filling rate was shorter in group 2 patients $(104$ (39) $v$ $69(29) \mathrm{ms}, \mathrm{p}=0.02$ ) but time to peak ejection rate was similar in the two groups $(p=N S)$. There was no significant difference in $R R$ interval between the

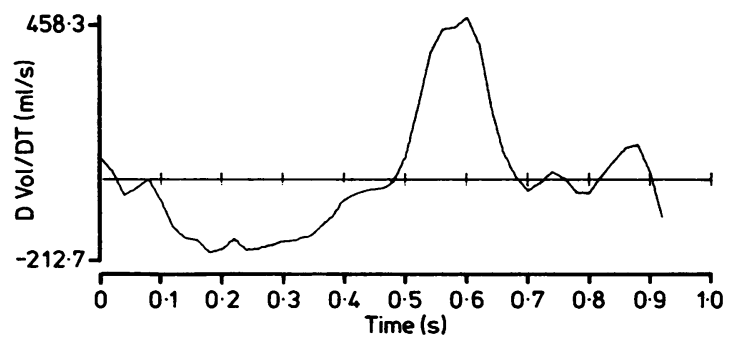

Fig 4 First derivative of the volume curve shown in fig 3. Peak rates of ventricular filling (DVol/DT) and emptying $(-D V o l / D T)$ are shown on the $y$ axis. 

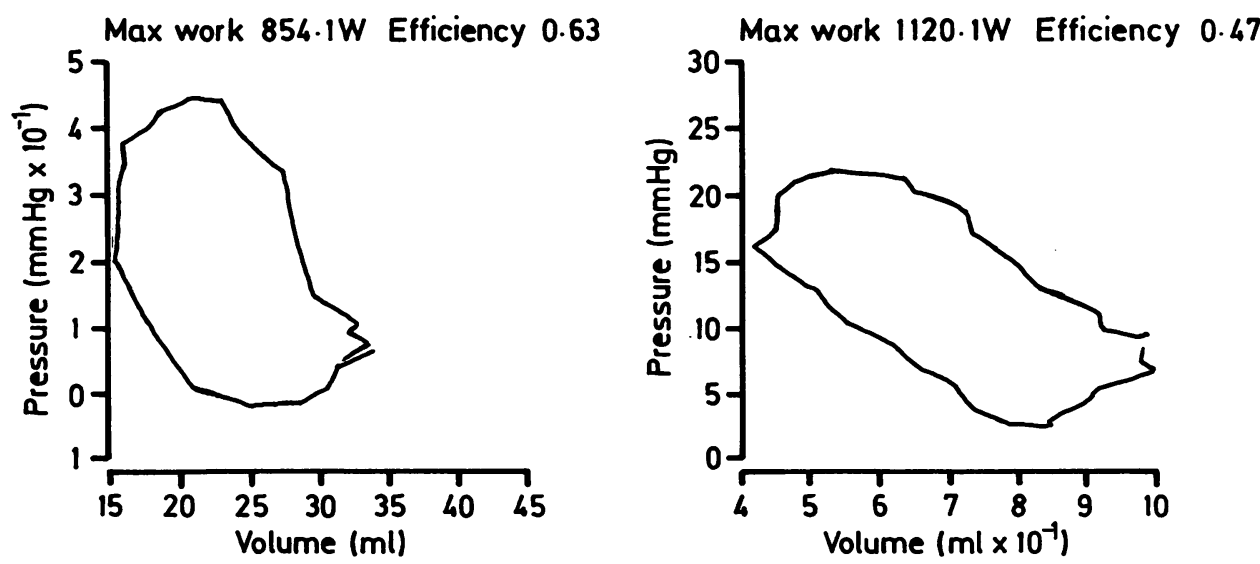

Fig 5 Pressure-volume loops obtained from two patients after repair. In both patients right ventricular volume increased as pressure fell. This represents pulmonary regurgitation and is more severe in the loop shown on the right.

two groups (group 1567 (169) $v 657$ (149) ms, p = NS).

There was no relation between any of these variables and the age at operation in group 2 but there were weak, non-significant relations between the age at study and end diastolic volume index, and a significant inverse relation with ejection fraction $(r=$ 0.49 and -0.5 respectively, both $p<0.1$ ).

\section{PRESSURE-VOLUME RELATIONS}

We have already described the changes in shape and characteristics of the right ventricular pressurevolume loop with pressure load. ${ }^{12}$ In this study a typical loop obtained before repair was more square or rectangular than the triangular or trapezoidal normal right ventricular pressure-volume loop which shows a well defined period of truly "isovolumic" relaxation. After repair and relief of $气$ pressure load, the shape of the loops became more normal (fig 5). The reduction in cycle efficiency (71 $\oplus$ (7) $v 56(9), \mathrm{p}<0.001)$ and systolic stroke work $(1.9 \%$ $(0.75)$ v $0.6(0.34) \mathrm{J} /$ beat $/ \mathrm{m}^{2}$ body surface area, $\mathrm{p}<$ ס $0.001)$ reflected these changes.

In nine of the 11 group 2 (repair) patients pulmonary regurgitation was seen as an increase in ventricular volume during pressure fall (see methods $\mathbb{Q}$ section). The pulmonary regurgitant fraction for the group was $28(19 \%)$ of the stroke volume. Pulmonary regurgitant volume was $15.5(14) \mathrm{ml} /$ beat $/ \mathrm{m}^{2}$ and correlated with end diastolic volume index $(r=0 \cdot 78$, $\mathrm{p}<0.01)$ and stroke volume index $(\mathrm{r}=0.85, \mathrm{p}<$ $0.001)$ but not with ejection fraction $(r=0.01, p=\pi$ NS) (fig 6). There was a weaker, but significant, inverse relation between peak filling rate and pulmonary regurgitant volume $(r=-0.54, p<0.05)$.

Table 1 Data of 12 patients with tetralogy of Fallot (group 1)

\begin{tabular}{|c|c|c|c|c|c|c|c|c|c|c|c|}
\hline Case No & Shunt & $\begin{array}{l}\text { Age } \\
\text { (mnth) }\end{array}$ & $\begin{array}{l}E D V I \\
\left(m l / m^{2}\right)\end{array}$ & $\begin{array}{l}E S V I \\
\left(\mathrm{ml} / \mathrm{m}^{2}\right)\end{array}$ & $\begin{array}{l}S V I \\
\left(m l / m^{2}\right)\end{array}$ & $\begin{array}{l}E F \\
(\%)\end{array}$ & $\begin{array}{l}P E R / E D V \\
\left(s^{-1}\right)\end{array}$ & $\begin{array}{l}t P E R \\
\text { (ms) }\end{array}$ & $\begin{array}{l}P F R / E D V \\
\left(s^{-t}\right)\end{array}$ & $\begin{array}{c}t P F R \\
\text { (ms) }\end{array}$ & $\begin{array}{l}R R \\
(m s)\end{array}$ \\
\hline $\begin{array}{r}1 \\
2 \\
3 \\
4 \\
5 \\
6 \\
7 \\
8 \\
9 \\
10 \\
11 \\
12\end{array}$ & $\begin{array}{l}\overline{+} \\
\overline{+} \\
+ \\
\overline{+} \\
+ \\
+ \\
+ \\
+ \\
+ \\
-\end{array}$ & $\begin{array}{r}8 \\
12 \\
19 \\
24 \\
47 \\
72 \\
84 \\
36 \\
48 \\
13 \\
84 \\
60\end{array}$ & $\begin{array}{l}72 \\
85 \\
36 \\
52 \\
92 \\
52 \\
67 \\
59 \\
81 \\
70 \\
56 \\
38\end{array}$ & $\begin{array}{l}33 \\
39 \\
12 \\
11 \cdot 5 \\
19 \\
12 \\
17 \\
26 \\
41 \\
36 \\
24 \\
14\end{array}$ & $\begin{array}{l}39 \\
46 \\
24 \\
40 \cdot 5 \\
73 \\
40 \\
50 \\
33 \\
40 \\
34 \\
32 \\
24\end{array}$ & $\begin{array}{l}53 \\
54 \\
66 \\
77 \\
73 \\
76 \\
74 \\
54 \\
48 \\
48 \\
58 \\
63\end{array}$ & $\begin{array}{l}4 \cdot 7 \\
3 \cdot 2 \\
5 \cdot 0 \\
4 \cdot 6 \\
7 \cdot 6 \\
4 \cdot 3 \\
2 \cdot 7 \\
3 \cdot 2 \\
2 \cdot 6 \\
2 \cdot 8 \\
4 \cdot 4 \\
5 \cdot 0\end{array}$ & $\begin{array}{l}130 \\
130 \\
120 \\
120 \\
100 \\
150 \\
180 \\
100 \\
100 \\
210 \\
150 \\
140\end{array}$ & $\begin{array}{c}7 \cdot 4 \\
10.5 \\
5 \cdot 2 \\
7 \cdot 25 \\
11 \cdot 1 \\
8 \cdot 2 \\
5 \cdot 8 \\
2.9 \\
3 \cdot 7 \\
3 \cdot 5 \\
6 \cdot 2 \\
5 \cdot 2\end{array}$ & $\begin{array}{r}120 \\
60 \\
100 \\
100 \\
50 \\
40 \\
180 \\
110 \\
120 \\
120 \\
110 \\
140\end{array}$ & $\begin{array}{l}700 \\
480 \\
600 \\
560 \\
360 \\
460 \\
920 \\
600 \\
500 \\
800 \\
400 \\
420\end{array}$ \\
\hline \multicolumn{2}{|c|}{ Mean (SD) } & $42(28)$ & $63(18)$ & $24(11)$ & $40(13)$ & $62(11)$ & $4 \cdot 2(1 \cdot 4)$ & $136(33)$ & $6.4(2.6)$ & 104 (39) & 567 (169) \\
\hline
\end{tabular}
EDVI, end diastolic volume index; EF, ejection fraction; ESVI, end systolic volume index; PER, peak ejection rate; PFR, peak filling rate;
SVI, stroke volume index; tPER, time to PER; tPFR, time to PFR. 
Table 2 Data on 12 patients after repair of tetralogy of Fallot (group 2)

\begin{tabular}{|c|c|c|c|c|c|c|c|c|c|c|c|}
\hline Case No & Shunt & $\begin{array}{l}\text { Age } \\
\text { (mnth) }\end{array}$ & $\begin{array}{l}E D V I \\
\left(m l / m^{2}\right)\end{array}$ & $\begin{array}{l}E S V I \\
\left(m l / m^{2}\right)\end{array}$ & $\begin{array}{l}S V I \\
\left(\mathrm{ml} / \mathrm{m}^{2}\right)\end{array}$ & $\begin{array}{l}E F \\
(\%)\end{array}$ & $\begin{array}{l}P E R / E D V \\
\left(s^{-1}\right)\end{array}$ & $\begin{array}{c}t P E R \\
(m s)\end{array}$ & $\begin{array}{l}P F R / E D \\
\left(s^{-1}\right)\end{array}$ & $\begin{array}{c}t P F R \\
\text { (ms) }\end{array}$ & $\begin{array}{l}R R \\
(m s)\end{array}$ \\
\hline $\begin{array}{r}1 \\
2 \\
3 \\
4 \\
5 \\
6 \\
7 \\
8 \\
9 \\
10 \\
11 \\
12\end{array}$ & $\begin{array}{l}+ \\
- \\
+ \\
- \\
+ \\
+ \\
- \\
- \\
- \\
+ \\
+ \\
-\end{array}$ & $\begin{array}{r}108 \\
36 \\
120 \\
180 \\
24 \\
19 \\
120 \\
132 \\
36 \\
108 \\
48 \\
144\end{array}$ & $\begin{array}{r}71 \\
42 \\
50 \\
136 \\
53 \\
91 \\
101 \\
91 \\
127 \\
106 \\
59 \\
130\end{array}$ & $\begin{array}{l}38 \\
15 \\
18 \cdot 5 \\
17 \cdot 9 \\
23 \cdot 5 \\
45 \\
47 \\
46 \\
52 \\
47 \\
25 \\
60\end{array}$ & $\begin{array}{l}33 \\
27 \\
31 \cdot 5 \\
57 \\
29 \cdot 5 \\
46 \\
54 \\
45 \\
75 \\
59 \\
34 \\
70\end{array}$ & $\begin{array}{l}46 \\
64 \\
63 \\
42 \\
55 \\
50 \\
53 \\
49 \\
59 \\
55 \\
57 \\
53\end{array}$ & $\begin{array}{l}3.3 \\
3.4 \\
2.7 \\
2.0 \\
3.0 \\
3.6 \\
2.0 \\
2 \cdot 2 \\
2.7 \\
2.2 \\
2.7 \\
2.0\end{array}$ & $\begin{array}{r}110 \\
200 \\
80 \\
110 \\
120 \\
110 \\
70 \\
150 \\
100 \\
150 \\
170 \\
100\end{array}$ & $\begin{array}{l}3.4 \\
6 \cdot 3 \\
4.4 \\
2 \cdot 2 \\
5 \cdot 1 \\
4 \cdot 8 \\
2 \cdot 0 \\
2 \cdot 6 \\
2 \cdot 6 \\
3.5 \\
4.5 \\
2 \cdot 3\end{array}$ & $\begin{array}{r}50 \\
40 \\
50 \\
30 \\
100 \\
60 \\
60 \\
110 \\
50 \\
90 \\
120 \\
70\end{array}$ & $\begin{array}{l}500 \\
700 \\
700 \\
780 \\
480 \\
440 \\
640 \\
920 \\
780 \\
800 \\
540 \\
600\end{array}$ \\
\hline \multicolumn{2}{|c|}{ Mean (SD) } & $90(54)$ & $88(33)$ & $41(19)$ & $47(16)$ & $54(6 \cdot 5)$ & $2.6(0.5)$ & $114(37)$ & $3.7(1.4)$ & $69(29)$ & 657 (149) \\
\hline
\end{tabular}

See footnote to table 1 for abbreviations.

\section{Discussion}

We calculated right ventricular volume by applying the regression equations obtained in a previous study that compared the right ventricular volume of a cast measured by fluid displacement with the volume derived from biplane angiograms. ${ }^{10}$ This regression equation may give rise to errors if loading conditions or the myocardium are abnormal. Such errors are likely to be small, however, ${ }^{13}$ and fig 2 shows the advantages of our multiple slice method under such circumstances. It is possible that other multiple slice methods such as those where the right ventricle is divided into only 10 slices $^{1314}$ or those with a fixed slice depth of $0.5 \mathrm{~cm}^{15}$ may not take account of small variations in ventricular shape (as in this case where there is an outflow tract aneurysm). We divided the right ventricle into 40 slices, which ensured that such abnormalities were incorporated into the volume calculation. Furthermore, small errors in the estimation of absolute volume should not have influenced measurements of relative changes in volume. We believe that this is a justifiable method of measuring frame by frame changes in right ventricular volume.

Two previous preoperative studies in patients with tetralogy have shown that right ventricular end diastolic volume and ejection fraction are essentially normal. ${ }^{35}$ A systemic to pulmonary shunt, however, results in a higher right ventricular volume and lower ejection fraction. ${ }^{5}$ The results of the present study largely confirm these findings; end diastolic volume corrected for body surface area and ejection fraction
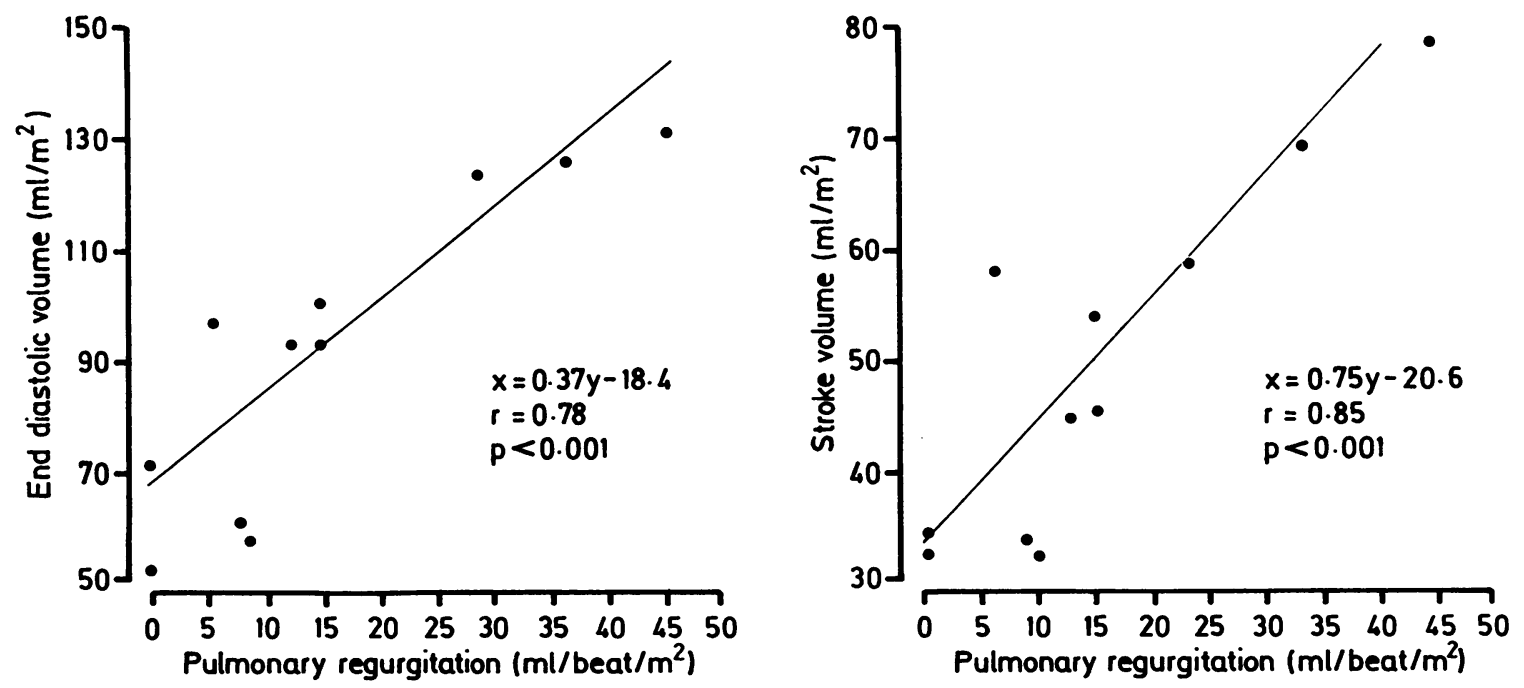

Fig 6 Graphs showing the relation between pulmonary regurgitant volume and end diastolic volume index (left) and end systolic volume index (right). 
were not significantly different from normal values, ${ }^{14}$ but there was a tendency for end diastolic volume to be higher and for ejection fraction to be lower in the six patients with a modified Blalock-Taussig shunt than in the patients without a shunt.

Right ventricular end diastolic volume was increased and the ejection fraction was lower in the group that had a repair operation. Similar changes have been demonstrated by others. ${ }^{378}$ It has been suggested that these may be the result of a primary myocardial abnormality, ${ }^{3}$ secondary to the diffuse myocardial fibrosis that was found in these patients. ${ }^{16}$ Some workers, ${ }^{8}$ but not others,${ }^{6}$ have shown a lower ejection fraction in the subgroup of patients who require right ventricular outflow tract patching than in those who require only an infundibulectomy. The effect of residual right ventricular volume load is also important. ${ }^{379}$ The most frequent cause of this will be pulmonary regurgitation, because disruption of the architecture of the outflow tract and pulmonary valve at the time of repair is almost inevitable. This is supported by the data in the present study which show that up to $85 \%$ of patients have significant pulmonary regurgitation, often in the absence of clinical signs. Unfortunately previous studies of the effect of pulmonary regurgitation are difficult to interpret. This is largely because of the difficulty investigators experienced in quantifying the degree of regurgitation present. In one study, where pulmonary regurgitation was assessed clinically, there was a significant reduction in right ventricular ejection fraction when it was "moderate or severe".. In another, where it was assessed subjectively from pulmonary root angiograms, the degree of pulmonary regurgitation was not related to ejection fraction. ${ }^{7}$ The methods used in both these studies are subject to criticism. Lange et al used a videodensitometric method to assess the degree of pulmonary regurgitation in their patients after repair. ${ }^{3}$ Their study showed that as the volume load increased the ejection fraction fell (however, there is a discrepancy between the results in their tables and those shown in the text and figures). It was difficult to interpret the results of this study because they grouped together data from patients with right ventricular volume load caused by pulmonary regurgitation, residual ventricular septal defect, or both (a method of analysis which was subsequently criticised ${ }^{17}$ ) and they included patients with large residual outflow tract gradients (the mean outflow tract gradient was $>17 \mathrm{~mm} \mathrm{Hg}$ in all their postoperative subgroups).

The results of our study go some way to answering several questions about the pathophysiology of right ventricular dysfunction after repair of tetralogy of Fallot.

We selected our patients chiefly because they were symptom free, and we studied only patients who showed no residual ventricular septal defect or $\frac{T}{\Phi}$ important obstruction of the right ventricular outflow tract. In 11 of the 12 patients the outflow $c$ tract was enlarged with a patch but none required $\ddot{\Rightarrow}$ transannular patching. They were, therefore, a $\stackrel{?}{\rightarrow}$ relatively uniform population.

We were also able to get an accurate estimate of the volume of pulmonary regurgitation from the pressure-volume loops. Nine of the 11 patients in whom we obtained pressure-volume loops had an increase of in right ventricular volume of $>5 \mathrm{ml} / \mathrm{beat} / \mathrm{m}^{2}$ during $\vec{\circ}$ the decline in right ventricular pressure. The increase in volume before the point at which the right $\vec{\omega}$ ventricular pressure was equivalent to the peak right atrial pressure-that is before the tricuspid valve could open-must represent pulmonary regurgitation (in the absence of left to right shunting or continued injection of contrast medium). And $v$ although this volume is not the total regurgitant $ᄋ$ volume, it should be an accurate index of the degree of regurgitation.

We found a highly significant correlation between pulmonary regurgitant volume and both end diastolic volume and stroke volume index, but no relation with ejection fraction. Although this observation is at variance with the findings of Lange $e t a l^{\beta}$ the methodological weaknesses of their study make it difficult to compare data. Furthermore, some of Lange et al's patients had much greater right ventricular volume load than our patients. Indeed there was no significant difference between their two subgroups with less severe volume loading, which suggests that there may be a threshold above which pulmonary regurgitation reduces ejection fraction.

What then is the cause of the reduced ejection fraction in most patients after repair of tetralogy of Fallot? It would be surprising if the contractile properties of the right ventricle were not altered when part of its wall is replaced with a non-contractile material. We may not need to invoke a possible adverse effect of pulmonary regurgitation. Graham $e$ t 9 al show that there was no difference in ejection fraction after repair if an outflow tract patch was not used. ${ }^{8}$ Those who do not require outflow tract patching may be less likely to have postoperative pulmonary regurgitation, but unfortunately Graham et al were unable to quantify the degree of pulmonary regurgitation in their patients. Their findings and our own data, showing no correlation between pul- $c$ monary regurgitation and right ventricular ejection $\overparen{\Phi}$ fraction and no difference in ejection fraction be- ? tween the group of six patients with the lower 0 regurgitant volumes and the remainder seem to suggest that the direct effects of operation are most important.

We suggest that the impairment of ventricular function in most patients after repair of tetralogy of 
Fallot is primarily an effect of the non-contractile outflow tract patch rather than a consequence of mild or moderate pulmonary regurgitation. This suggestion is also supported by our finding that despite relief of right ventricular outflow tract obstruction, the peak rate of right ventricular ejection was also reduced after repair but was unrelated to the degree of pulmonary regurgitation.

In addition to these systolic abnormalities there were also abnormalities of diastolic function. Peak rate of ventricular filling and the time to peak filling were both significantly reduced in the repair group (group 2). This pattern is similar to that previously described for the left ventricle with ischaemic cardiomyopathy. ${ }^{18}$ Although this pattern may be explained by a reduction in diastolic compliance of the right ventricular myocardium secondary to the patch or myocardial fibrosis, it is perhaps more likely to be related to the higher end systolic volume of the right ventricle and its further distension before tricuspid valve opening, resulting from pulmonary regurgitation. The normal right ventricular end diastolic pressures and the strong inverse relation between peak filling rate and end systolic volume index in the repair group (but not in group 1) support this suggestion; however, it is likely that a combination of factors contributes to the overall impairment.

We found abnormalities of both systolic and diastolic indices of right ventricular function after repair of tetralogy of Fallot and a strong linear relation between the amount of pulmonary regurgitation and right ventricular end diastolic volume. The reduction in right ventricular ejection fraction after repair seemed to be related to the direct effects of operation rather than to pulmonary regurgitation in this selected group of patients. The effect of more severe or more prolonged postoperative pulmonary regurgitation is unknown. Further long term studies would be helpful.

We thank Graham Miller, Derek Gibson, and Susan Jones for their help in the performance of these studies, and David Hughes for the computer analysis of the data.

A N R is the holder of a British Heart Foundation project grant.

\section{References}

1 Pacifico AD, Bargeron LM, Kirklin JW. Primary correction of tetralogy of Fallot in children less than four years of age. Circulation 1973;48:1085-91.

2 Arciniegas EA, Farooki ZQ, Hakimi M, Perry BL,
Green EW. Early and late results of total correction of tetralogy of Fallot. J Thorac Cardiovasc Surg 1980; 80:770-8.

3 Lange PE, Onnasch DGW, Bernhard A, Heintzen PH. Left and right ventricular adaptation to right ventricular overload before and after surgical repair of tetralogy of Fallot. Am J Cardiol 1982;50:786-94.

4 Jarmakani JMM, Graham TP, Canent RV, Jewett PH. Left heart function in children before and after palliative or corrective surgery. Circulation 1972; 46:478-90.

5 Jarmakani JMM, Nakazawa $\mathrm{K}$, Isabel-Jones J, Marks RA. Right ventricular function in children with tetralogy of Fallot before and after aortic-to-pulmonary shunt. Circulation 1976;53:555-61.

6 Reduto LA, Berger HJ, Johnstone DE, et al. Radionuclide assessment of right and left ventricular exercise reserve after total correction of tetralogy of Fallot. $\mathrm{Am}$ J Cardiol 1980;45:1013-8.

7 Oku H, Shirotani H, Sunakawa A, Yokoyama T. Postoperative long-term results in total correction of tetralogy of Fallot: haemodynamics and cardiac function. Ann Thorac Surg 1986;41:413-8.

8 Graham TP, Cordell D, Atwood GF, et al. Right ventricular volume characteristics before and after palliative and reparative operation in tetralogy of Fallot. Circulation 1976;54:417-23.

9 Bove EL, Byrum CJ, Thomas FD, et al. The influence of pulmonary insufficiency on ventricular function following repair of tetralogy of Fallot. $J$ Thorac Cardiovasc Surg 1983;85:691-6.

10 Redington AN, Gray HH, Hodson ME, Rigby ML, Oldershaw PJ. Characterisation of the normal right ventricular pressure-volume relation by biplane angiography and simultaneous micromanometer pressure measurements. Br Heart J 1988;59:23-30.

11 Gibson DG, Brown DJ. Assessment of left ventricular systolic function in man from simultaneous echocardiographic and pressure measurements. $\mathrm{Br}$ Heart $J$ 1976;38:8-17.

12 Redington AN, Gray HH, Rigby ML, Oldershaw PJ. Changes in the right ventricular pressure-volume relationship with pressure loading [Abstract]. Circulation 1986;74 (suppl II):399.

13 Fisher EA, DuBrow IW, Hastreiter AR. Right ventricular volume in congenital heart disease. $\mathrm{Am} \mathrm{J}$ Cardiol 1975;36:67-75.

14 Graham TP, Jarkamani JM, Atwood GF, Canent RV. Right ventricular volume determinations in children. Circulation 1973;47:144-53.

15 Gentzler RD, Briselli MF, Gault JH. Angiographic estimation of right ventricular volume in man. Circulation 1974;50:324-30.

16 Krymsky LD. Pathologic anatomy of congenital heart disease. Circulation 1965;32:814-27.

17 Colan S. Ventricular function before and after repair of tetralogy of Fallot [Letter]. Am J Cardiol 1983; 51:1568.

18 Hui WKK, Gibson DG. Mechanisms of reduced left ventricular filling rate in coronary artery disease. $\mathrm{Br}$ Heart $J$ 1983;50:362-71. 